\title{
Antimicrobial susceptibility of invasive and lower respiratory tract isolates of Streptococcus pneumoniae, 1998 to 2007
}

\author{
Otto G Vanderkooi $M D^{1,2,3}$, Athena McConnell MD ${ }^{1,3}$, Deirdre L Church $M D^{2,3}$, James D Kellner $M D^{1,3}$
}

\begin{abstract}
OG Vanderkooi, A McConnell, DL Church, JD Kellner. Antimicrobial susceptibility of invasive and lower respiratory tract isolates of Streptococcus pneumoniae, 1998 to 2007. Can J Infect Dis Med Microbiol 2009;20(4):e139-e144.
\end{abstract}

Previous surveys of antimicrobial resistance in Streptococcus pneumoniae have found differences depending on source of isolate (eg, higher resistance in lower respiratory tract [LRT] versus invasive isolate) and age (higher resistance in children versus adults). Susceptibility profiles in the Calgary Health Region (approximately 1.25 million population) over a 10-year period were studied. Prospective laboratory-based population surveillance for $S$ pneumoniae disease has been conducted since 1998. Patient demographics and susceptibility testing were analyzed. In total, 2382 patient isolates were available for analysis from 1998 to 2007. Of these, 1170 isolates were invasive while 496 were LRT. Patient age distribution was: younger than five years, $14 \%$; five to 17 years, $6 \%$; 18 to 64 years, $56 \%$; and 65 years or older, $24 \%$. Mean patient age was 44.8 years and $60.0 \%$ were male. The overall incidence of nonsusceptibility was: penicillin, $8.2 \%$; amoxicillin, $0.3 \%$; cefuroxime, $6.2 \%$; ceftriaxone, $1.7 \%$; erythromycin, $8.8 \%$; trimethoprimsulfamethoxazole (TMP-SMX), 25.6\%; clindamycin, $2.3 \%$; and levofloxacin, $0.2 \%$. Overall resistance rates were stable, except for increasing erythromycin resistance from 5.4\% (1998) to a high of $14.2 \%(2004)(\mathrm{P}=0.007)$. Isolates that were nonsusceptible to penicillin or TMP-SMX were more likely to be multidrug resistant $(\mathrm{P}<0.001)$ compared with penicillin- or TMP-SMX-susceptible isolates. Compared with invasive isolates, LRT isolates showed more resistance to penicillin, TMP-SMX, cefuroxime and erythromycin, and were more likely to be multidrug resistant. Isolates from children younger than five years of age are more likely to be multidrug resistant and resistant to erythromycin and cefotaxime. Ongoing surveillance of $S$ pneumoniae isolates is important because resistance rates vary by source and patient age among health care regions.

Key Words: Antimicrobial susceptibility; Lower respiratory tract infection; Streptococcus pneumoniae

Streptococcus pneumoniae remains a leading cause of morbid-

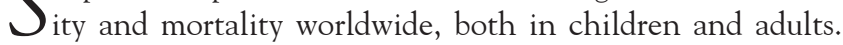
Clinical manifestations of disease associated with this pathogen vary, and include meningitis, bacteremia, pneumonia and otitis media (1-6). Penicillin has been the drug of choice for treatment of pneumococcal infections, but penicillinnonsusceptible (NS; intermediate + resistant) isolates of $S$ pneumoniae (PNSP) have been reported with increasing frequency from many parts of the world (7). Of even more concern is that PNSP are more likely than penicillin-susceptible strains to be NS to other classes of antimicrobials (7). The prevalence of resistance varies from country to country, and also within countries. PNSP rates are reportedly 28\% in Europe

\section{La susceptibilité antimicrobienne d'isolats envahissants et provenant des voies respiratoires inférieures de Streptococcus pneumoniae entre 1998 et 2007}

\begin{abstract}
Selon des enquêtes antérieures, on a constaté des différences de résistance antimicrobienne du Streptococcus pneumoniae selon la source de l'isolat (p. ex., plus forte résistance dans les voies respiratoires inférieures [VRI] que dans les isolats envahissants) et l'âge (plus forte résistance chez les enfants que chez les adultes). On a étudié les profils de susceptibilités dans la région sanitaire de Calgary (population d'environ 1,25 million d'habitants) sur une période de dix ans. On procède à la surveillance prospective en laboratoire de la maladie à $S$ pneumoniae depuis 1998. On a analysé la démographie des patients et les tests de susceptibilité. Au total, 2382 isolats de patients étaient disponibles à l'analyse entre 1998 et 2007. De ce nombre, 1170 isolats étaient envahissants et 496 provenaient des VRI. La distribution des patients selon l'âge se répartissait comme suit : $14 \%$ de moins de cinq ans, $6 \%$ de cinq à 17 ans, $56 \%$ de 18 à 64 ans et $24 \%$ de 65 ans ou plus. L'âge moyen des patients était de 44,8 ans, dont $60 \%$ d'hommes. L'incidence globale de non-susceptibilité était de 8,2\% pour la pénicilline, de 0,3\% pour l'amoxicilline, de $6,2 \%$ pour le céfuroxime, de $1,7 \%$ pour la ceftriaxone, de 8,8 \% pour l'érythromicine, de 25,6 \% pour le triméthoprim-sulfaméthoxazole (TMP-SMX), de 2,3\% pour la clindamycine et de $0,2 \%$ pour la lévofloxacine. Les taux de résistance globaux étaient stables, sauf pour l'érythromycine, dont la résistance est passée de 5,4\% (1998) à un pic de 14,2\% (2007) $(\mathrm{P}=0,007)$. Les isolats non susceptibles à la pénicilline ou au TMP-SMX risquaient davantage d'être multirésistants $(\mathrm{P}<0,001)$ que ceux qui y étaient susceptibles. Par rapport aux isolats envahissants, ceux provenant des VRI étaient plus résistants à la pénicilline, au TMP-SMX, au céfuroxime et à l'érythromycine et plus susceptibles d'être multirésistants. Les isolats prélevés sur des enfants de moins de cinq ans étaient plus susceptibles d'être multirésistants et résistants à l'érythromycine et à la céfotaxime. Il est important d'assurer une surveillance continue des isolats de $S$ pneumoniae parce que, dans les régions sanitaires, les taux de résistance varient selon la source et l'âge des patients
\end{abstract}

and Latin America, 31\% in Malaysia and 34\% in the United States $(8,9)$. Regional variation in pneumococcal antimicrobial susceptibility has been shown to occur in the United States, Europe and Canada (10-14).

Data from Canadian sources over the past 30 years show that resistance of $S$ pneumoniae to penicillin and other antimicrobials is increasing in this country. In the late 1970s, 2.4\% of $S$ pneumoniae isolates in Alberta and the Northwest Territories were penicillin NS (15). More than 25 years later, penicillin NS rates across Canada are $11.7 \%$ to $15 \%$, with $3.3 \%$ to $6.5 \%$ of pneumococcal isolates being penicillin resistant $(14,16,17)$. Surveillance data of $S$ pneumoniae isolates submitted to participating laboratories in 2002 revealed penicillin

\footnotetext{
${ }^{1}$ Alberta Children's Hospital; ${ }^{2}$ Calgary Laboratory Services; ${ }^{3}$ University of Calgary, Calgary, Alberta

Correspondence: Dr Otto G Vanderkooi, Division of Infectious Diseases, Alberta Children's Hospital, 2888 Shaganappi Trail Northwest, Calgary,

Alberta T3B 6A8. Telephone 403-955-7407, fax 403-955-3045, e-mail ovanderk@ucalgary.ca
} 
resistance rates of $19 \%$ in Atlantic Canada, $14 \%$ to $16 \%$ in Central Canada, and $12 \%$ to $18 \%$ in Western Canada (14).

Because antimicrobial resistance in $S$ pneumoniae is variable with respect to geographic area and is increasing, continued local surveillance of this problem is required to guide appropriate antimicrobial choices. The present report describes the results of antimicrobial susceptibility rates of $S$ pneumoniae isolates for cases of invasive and lower respiratory tract (LRT) disease in the Calgary Health Region (CHR) from 1998 to 2006.

\section{METHODS}

\section{Study design}

Population-based surveillance of invasive and LRT $S$ pneumoniae infections has been conducted in the CHR, one of nine regional health authorities in Alberta, since January 1, 1998, by the Calgary Area Streptococcus pneumoniae Epidemiology Research (CASPER) group. The CHR is an integrated, publicly funded health care system that encompasses the hospitals within the city of Calgary as well as the medical centres serving a large rural area surrounding the city (population 1,111,614 in 2007) (18).

Population-based surveillance is made possible in the CHR by Calgary Laboratory Services (CLS), a centralized regional laboratory service that provides clinical microbiology services to both hospitalized and ambulatory patients.

$S$ pneumoniae isolates from invasive and LRT infections collected at the CLS from January 1, 1998, to December 31, 2007, were included in the study. Patients were deemed to be CHR residents on the basis of town of residence listed in the admission and laboratory records. If this information was unavailable, patients with Alberta health care numbers were considered to be CHR residents if the culture was submitted to a collection site within the CHR boundaries. The study was approved by the Conjoint Health Research Ethics Board of the University of Calgary before commencement.

The date of collection, specimen source, demographic information, serotype and antimicrobial susceptibility are collected for each $S$ pneumoniae case identified by CLS. For all invasive cases, chart reviews were performed to collect clinical information. Chart reviews were conducted prospectively as of August 1, 2003, and retrospectively for earlier cases. Patients and/or their parents or next of kin were also interviewed as part of the prospective component.

\section{Laboratory methods}

Isolates were confirmed to be $S$ pneumoniae by standard methodology including Gram stain, colonial morphology on blood agar, bile solubility, susceptibility to optochin and pneumococcal antibody agglutination (Phadebact Pneumococcus, Boule Diagnostic AN, Sweden). Susceptibility testing was performed by broth microdilution utilizing 96-well panels (PML Microbiological Inc, Canada) and results were interpreted according to Clinical and Laboratory Standards Institute guidelines (19-21). Cefprozil susceptibility testing continued until July 2004. Telithromycin susceptibility testing started in 2004 and is ongoing.

Invasive $S$ pneumoniae infection was defined as the isolation of $S$ pneumoniae from a normally sterile body site. LRT $S$ pneumoniae infection was defined as the isolation of $S$ pneumoniae from bronchoalveolar lavage, bronchial wash, tracheal aspirate, endotracheal tube aspirate and protected brush specimen. Only one isolate was included for analysis per episode (defined as isolates collected within 30 days of each other). In the event that $S$ pneumoniae was isolated from an invasive and LRT specimen collected during the same episode, only the invasive isolate was included in the analysis. NS S pneumoniae isolates are those with susceptibility tests indicating intermediate or resistant susceptibility according to the Clinical and Laboratory Standards Institute guidelines (19-21). Multidrug resistant (MDR) S pneumoniae isolates were NS to antimicrobials from three or more of the following classes: beta-lactams, sulfonamides, macrolides/ lincosamides, tetracycline, fluoroquinolones, glycopeptides and streptogramins.

\section{Data analysis}

Data were analyzed using SPSS 16.0 for Mac OS X (SPSS Inc, USA). Categorical data were summarized as proportions and continuous data were summarized as means and medians with ranges, and standard deviations. Differences between groups were tested by the $\chi^{2}$ test for categorical variables and Student's $t$ test for continuous variables. Logistic regression was used to analyze trends in antimicrobial susceptibility over the study period. Differences were considered statistically significant at a $\mathrm{P}<0.05$.

\section{RESULTS}

A total of 2382 isolates were recovered by CLS between January 1, 1998, and December 31, 2007. Analysis was performed on 1666 episodes, excluding 716 isolates for residence outside of the CHR ( $n=314)$, not $S$ pneumoniae $(n=40)$, multiple isolates from a single episode $(n=308)$, not saved $(n=8)$, nonviability of the organism $(n=13)$, and isolates that were neither invasive nor LRT in origin $(n=33)$.

There were 1170 (70.2\%) invasive isolates and 496 (29.8\%) LRT isolates. Invasive isolate sources were obtained from blood $(n=1037[88.6 \%])$, cerebrospinal fluid $(n=57$ [4.9\%]), pleural fluid $(n=52[4.4 \%])$, synovial fluid $(n=11[0.9 \%])$, peritoneal fluid $(n=8[0.7 \%])$, lung tissue $(n=2[0.2 \%])$, brain tissue $(n=1$ $[0.1 \%])$ and vitreous fluid $(n=2[0.2 \%])$. LRT isolates were recovered from bronchoalveolar lavages/bronchial washes $(n=259[52.2 \%])$, endotracheal tube aspirates $(n=220$ [44.4\%]), tracheal aspirates $(n=16[3.2 \%])$ and protected brush specimens $(n=1[0.2 \%])$.

One thousand $(60.0 \%)$ isolates were from male patients, with no sex recorded for one patient. Mean $( \pm$ SD) patient age was $44.8 \pm 26.0$ years (range 0.04 to 105.2 years). LRT isolates came from patients who were younger (mean 42.3 years versus 45.9 years, $\mathrm{P}=0.046$ ) than those patients with invasive isolates, and were also more likely to be male $(66.3 \%$ versus $57.4 \%$, $\mathrm{P}=0.001)$. Two hundred forty $(14.4 \%)$ were from patients younger than five years of age, $94(5.6 \%)$ from patients five to 17 years of age, $928(55.7 \%)$ from patients 18 to 64 years of age, and $404(24.2 \%)$ from patients 65 years of age and older.

Table 1 demonstrates NS rates for all antimicrobials tested. Isolates that were NS to penicillin and trimethoprimsulfamethoxazole (TMP-SMX) also showed higher NS rates to penicillin, TMP-SMX, parenteral cefuroxime, cefotaxime and erythromycin (Figure 1). Among penicillin and TMP-SMX NS isolates, $40.1 \%$ and $14.8 \%$, respectively, were MDR $(\mathrm{P}<0.001$ in both cases). Antimicrobial resistance rates for the study 
TABLE 1

Antimicrobial susceptibility of Streptococcus pneumoniae isolates in Calgary, Alberta, from 1998 to 2007 ( $n=1666)$

\begin{tabular}{|c|c|c|c|}
\hline & $\begin{array}{c}\text { Susceptible, } \\
\text { n (\%) }\end{array}$ & $\begin{array}{c}\text { Intermediate, } \\
\text { n (\%) }\end{array}$ & $\begin{array}{l}\text { Resistant, } \\
\text { n (\%) }\end{array}$ \\
\hline Penicillin & $1529(91.8)$ & $122(7.3)$ & $15(0.9)$ \\
\hline Amoxicillin* & $1661(99.7)$ & $5(0.3)$ & 0 \\
\hline Cefuroxime - oral & $1571(94.3)$ & $34(2.0)$ & $61(3.7)$ \\
\hline Cefuroxime - parenteral & $1562(93.8)$ & $9(0.5)$ & $95(5.7)$ \\
\hline Cefprozil $^{\dagger}$ & $941(93.9)$ & $38(3.8)$ & $23(2.3)$ \\
\hline Cefotaxime & $1632(98.0)$ & $32(1.9)$ & $2(0.1)$ \\
\hline Ceftriaxone & $1637(98.3)$ & $27(1.6)$ & $2(0.1)$ \\
\hline TMP-SMX & $1240(74.4)$ & $288(17.3)$ & $138(8.3)$ \\
\hline Erythromycin & $1520(91.2)$ & $15(0.9)$ & $131(7.9)$ \\
\hline Clindamycin & $1627(97.7)$ & $5(0.3)$ & $34(2.0)$ \\
\hline Tetracycline & 1585 (95.1) & $16(1.0)$ & $65(3.9)$ \\
\hline Meropenem & $1637(98.3)$ & $21(1.3)$ & $8(0.5)$ \\
\hline Levofloxacin & $1663(99.8)$ & $0(0.0)$ & $3(0.2)$ \\
\hline Gatifloxacin ${ }^{\ddagger}$ & $1321(99.8)$ & $3(0.2)$ & $0(0.0)$ \\
\hline Moxifloxacin $§$ & $915(99.8)$ & $2(0.2)$ & $0(0.0)$ \\
\hline Quinupristin/dalfopristin & $1259(100.0)$ & $0(0.0)$ & $0(0.0)$ \\
\hline Vancomycin & $1666(100.0)$ & $0(0.0)$ & $0(0.0)$ \\
\hline
\end{tabular}

*Susceptibility testing to amoxicillin to the end of 2005, followed by ampicillin for 2006 and following; ${ }^{\dagger}$ Missing $n=664$; ${ }^{\ddagger}$ Missing $n=342$; ${ }^{8}$ Missing $n=749$; "Missing n=407. TMP-SMX Trimethoprim-sulfamethoxazole

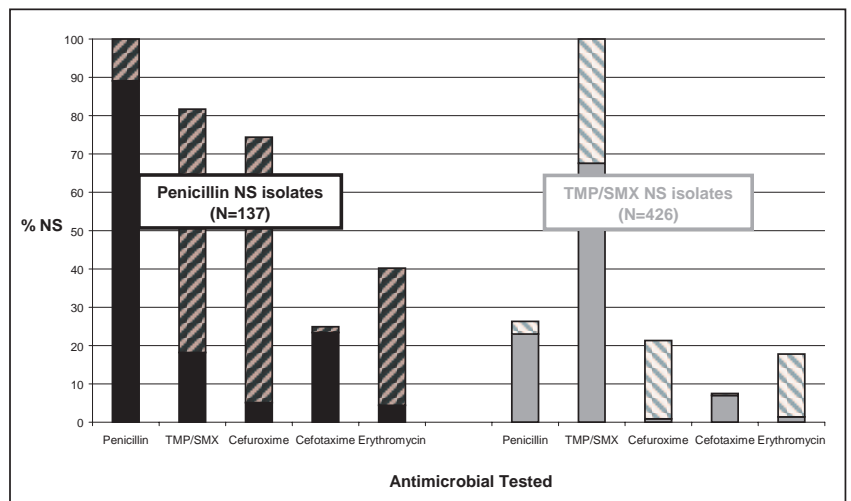

Figure 1) Antimicrobial susceptibility of pneumococcal isolates where either penicillin (shown in darker shading) or trimethoprimsulfamethoxazole (TMP-SMX, shown in lighter shading) is nonsusceptible (NS). Isolates that are NS to either penicillin or TMP-SMX are more likely to be NS to all of compared antibiotics than penicillin- or TMP-SMX-susceptible isolates (in all cases, $P<0.001$ ). (Solid bars: intermediate susceptibility; hashed bars: resistant)

period are shown in Figure 2. Susceptibility results comparing invasive and LRT isolates are demonstrated in Figure 3.

Rates of antimicrobial nonsusceptibility were significantly higher for respiratory isolates compared with invasive isolates.

A greater proportion of patients younger than five years of age versus those five years of age and older had isolates NS to penicillin $(12.5 \%$ versus $7.5 \%, \mathrm{P}=0.009)$, parenteral cefuroxime (9.2\% versus $5.8 \%, \mathrm{P}=0.04)$, cefotaxime $(3.8 \%$ versus. $1.8 \%$, $\mathrm{P}=0.04)$ and overall MDR S pneumoniae (7.5\% versus $3.8 \%$, $\mathrm{P}=0.009$ ) (Figure 4).

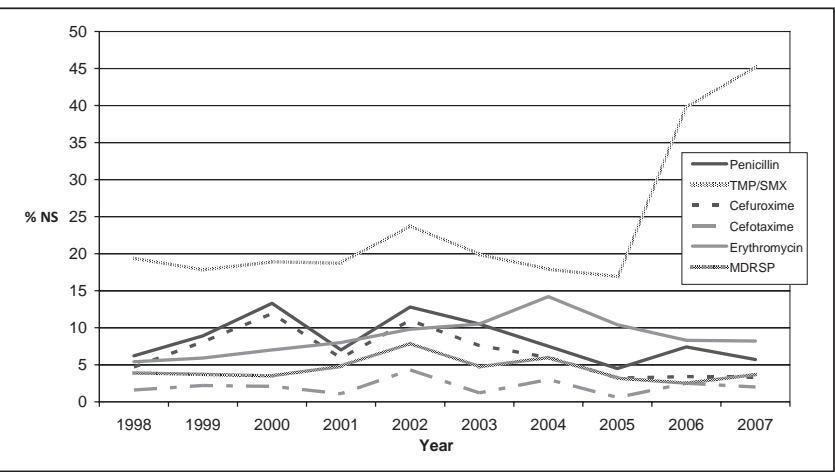

Figure 2) Antimicrobial nonsusceptibility (NS) of Streptococcus pneumoniae isolates in the Calgary Health Region, 1998 to 2007. NS proportions of penicillin, cefotaxime, erythromycin and multidrug resistance are stable over time ( $P \geq 0.05$ for change). A significant increase in NS for trimethoprim-sulfamethoxazole (TMP-SMX) $(P<0.001, O R=1.16,95 \%$ CI 1.12 to 1.21$)$ was seen over the study period. Cefuroxime resistance decreased over the same time interval ( $P=0.003, O R=0.90,95 \%$ CI 0.84 to 0.96). Before the 7-valent pneumococcal conjugate vaccine was introduced, there were no significant changes in NS rates. Looking only at the period following the introduction of PCV7 (2003 to 2007), there was a significant increase in the rate of TMP-SMX NS $(P<0.001, O R=1.46,95 \% \mathrm{CI} 1.31$ to 1.62$)$, and a significant decrease in the rate of cefuroxime NS ( $P=0.025, O R=0.78,95 \%$ CI 0.63 to 0.97). MDRSP Multidrug-resistant S pneumoniae

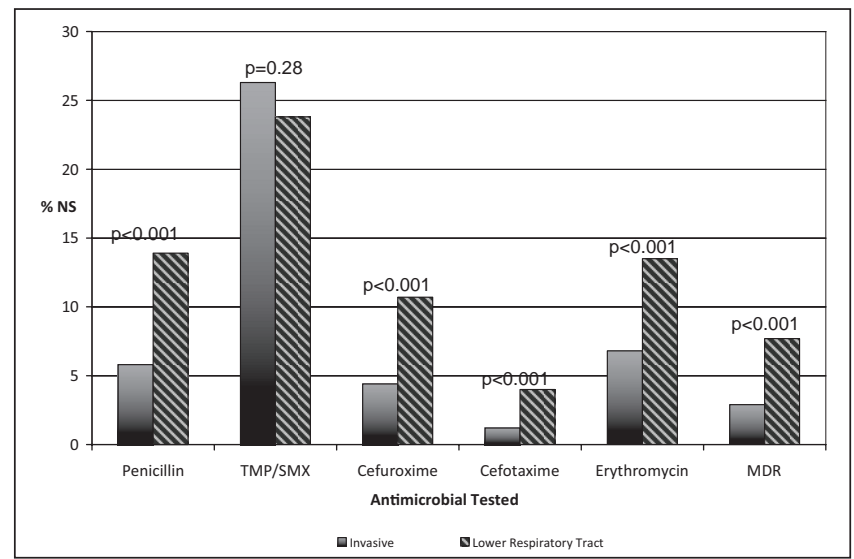

Figure 3) Antimicrobial nonsusceptibility (NS) of isolates of invasive versus lower respiratory tract Streptococcus pneumoniae isolates in Calgary, Alberta, 1998 to 2007. Multidrug-resistant (MDR) indicates resistance to three or more drug classes. TMP-SMX Trimethoprim-sulfamethoxazole

\section{DISCUSSION}

Rates of antimicrobial nonsusceptibility continue to be relatively low and stable when compared with data from other parts of Canada and other countries (11,12,14,22-24). Penicillin nonsusceptibility at $8 \%$ overall is one of the lowest reported rates in the modern era, with amoxicillin faring even more favourably with $0.3 \%$ intermediate susceptibility. Similarly, resistance rates among the other antimicrobials tested are low in our locale. 


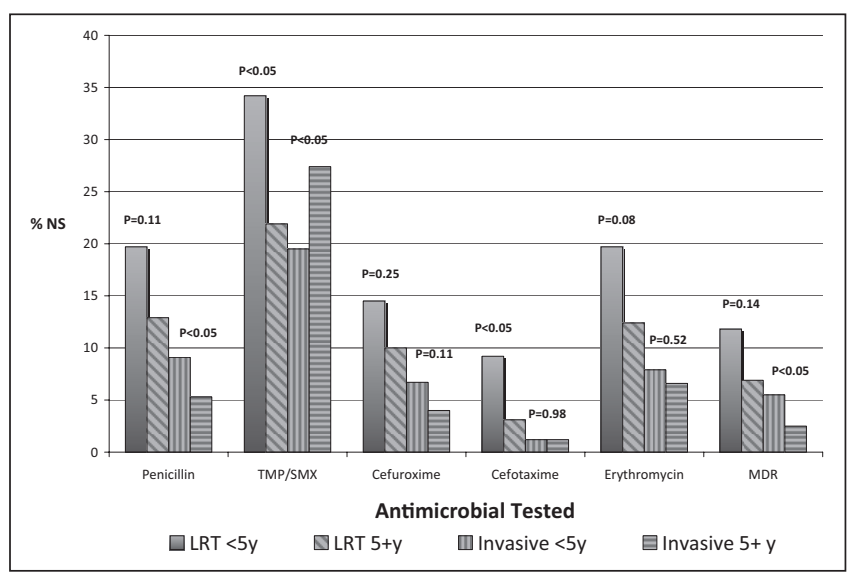

Figure 4) Comparison of antimicrobial susceptibility among lower respiratory tract (LRT) isolates and invasive isolates obtained from patients younger than and older than five years $(y)$ of age in the Calgary Health Region, 1998 to 2007. The comparisons between LRT isolates were significant $(P<0.05)$ for trimothoprim-sulfamethoxazole (TMP-SMX) and cefotaxime. The comparisons between invasive isolates were significant $(P<0.05)$ for penicillin, TMPSMX and multidrug-resistant (MDR) isolates. NS Nonsusceptible

In the CHR, NS rates to cefuroxime in invasive isolates from 2003 onward demonstrate significant decline (Figure 2). This was coincident with the introduction of the pneumococcal conjugate vaccine for infants and children in the fall of 2002. Similar results were reported following the introduction of 7-valent pneumococcal conjugate vaccine into the United States, including decreases in penicillin and ceftriaxone NS isolates (25-28). Proposed explanations for the fall in resistance rates among invasive isolates after immunization with the conjugate vaccine include reduction in nasopharyngeal colonization with resistant serotypes, and reduced selection pressure as a consequence of declining rates of pneumococcal disease leading to reduced antimicrobial use $(29,30)$. Extensive review in several of our group's previous studies have revealed a significant shift in nasopharyngeal carriage isolates among pediatric patients (31-33). Our relatively modest declines are likely due to low prevaccine resistance rates. However, this trend of decreasing resistance postvaccine may not continue as recent data have found some increased PNSP with increase resistance in nonvaccine serotypes $(34,35)$.

TMP-SMX rates of NS increased significantly in our adult population from 2005 to 2007 . This was due to an outbreak of serotype-specific (serotype 5) pneumococcal disease in the CHR among primarily homeless persons. This particular pneumococcal strain demonstrates intermediate susceptibility or resistance to TMP-SMX. This outbreak is described more fully in another publications, with a full manuscript in preparation $(36,37)$.

Our study found increased NS rates among LRT isolates when compared with isolates from invasive disease. Differences in NS rates as a function of isolate source have been reported by other authors in North America, Europe and Asia $(8,11,22,38)$. The Canadian Bacterial Surveillance Network also reported higher rates of penicillin NS for nonsterile compared with sterile isolates $(16.6 \%$ versus $12.4 \%, \mathrm{P}=0.005)$, with LRT specimens constituting $60 \%$ of the nonsterile isolates (14). Similarly, in Quebec, noninvasive isolates demonstrated higher rates of resistance to macrolides, penicillin and cephalosporins (39). The Tracking Resistance in the United States Today (TRUST) program in the United States reported higher rates of resistance among LRT isolates versus blood for penicillin, azithromycin, TMP-SMX and levofloxacin $(\mathrm{P}<0.0001$ for all comparisons) (12). Similar results were observed in the United Kingdom and Ireland, with an increased proportion of NS isolates from LRT isolates for penicillin (8.1\% versus $6.2 \%)$ and tetracycline $(7.6 \%$ versus $4.0 \%)$, similar rates for cefotaxime, clindamycin and amoxicillin, but decreased rates of erythromycin NS isolates (12\% versus $14.6 \%$ ) (40). When respiratory tract isolates are compared, specimens from the head, ear, eye, nose and throat show higher NS rates than those from the LRT (11,22-24).

Infections with serotype 19A, especially MDR 19A, have begun to have a significant impact in the epidemiology of pneumococcal infections in many jurisdictions $(34,35,41-43)$. Important infections seen with this serotype have included otitis media and invasive disease $(35,41)$. Up to 2007, serotype 19A and especially MDR 19A was an uncommon cause of invasive infection or LRT infection in Calgary (44). There were 12 cases of 19A disease from 1998 to 2006 and eight cases in 2007 (44).

Age was another significant factor determining NS rates in the CHR, with erythromycin and cefotaxime NS and MDR higher in pneumococcal isolates from young children (younger than five years of age). LRT isolates from children younger than five years of age were also more likely to be NS to TMPSMX, cefotaxime, erythromycin and MDR than isolates from older children and adults. This finding was also reported in Toronto, Ontario (45). Similarly, Powis et al (14) were able to show a significantly higher rate of fluoroquinolone NS among older adults compared with younger adults, but age was not associated with NS rates for the other antimicrobials. Six years of surveillance by the Canadian Respiratory Organism Susceptibility Study (CROSS) of pneumococcal isolates from the respiratory tract showed that age had no impact on penicillin, cefuroxime and clarithromycin NS rates (46). Weiss et al (39) examined the antimicrobial NS rates of pneumococcal isolates in Quebec from 2000 to 2001 showing younger age association with increased NS rates, but only for the macrolides (30\% versus $14.8 \%$, younger than 16 years of age versus 16 years of age and older, $\mathrm{P}<0.01)$. Other authors have also reported on age as a determinant of resistance $(12,47-49)$. The TRUST program showed that rates of resistance to penicillin, azithromycin, TMP-SMX and ceftriaxone were higher for isolates recovered from patients 18 years of age and younger versus patients 18 to 64 years of age $(\mathrm{P}<0.001)(12)$. Jones et al showed that isolates recovered from five or fewer years of age had higher rates of NS to penicillin, cefprozil, cefuroxime axetil, macrolides and TMP-SMX $(\mathrm{P}<0.05)$ than among the other age groups (47). Hoban et al (48) used data from 25 countries and demonstrated that isolates from infants younger than two years of age were more likely to be penicillin resistant (OR 1.98) and erythromycin resistant (OR 1.89) than isolates from adults.

An important strength of the present study is that the surveillance system identifies cases using a comprehensive 
centralized laboratory (CLS), which allows for a true population-based assessment of the antimicrobial susceptibility trends. A potential weakness is that respiratory tract samples are obtained in either severe cases or where there is therapeutic failure. The data from these samples are of particular importance because they reflect those clinical circumstances where adequate antimicrobials most indicated. The findings of our study have important implications for the empiric treatment of severe disease suspected to be caused by $S$ pneumoniae in our region. Overall, susceptibility rates to parenteral cefuroxime, cefotaxime and ceftriaxone are greater than $90 \%$. Because only $1.5 \%$ of invasive isolates are cefotaxime NS, this antimicrobial remains a good choice for empirical treatment of suspected invasive pneumococcal disease. Given the NS rate of $16 \%$ to parenteral cefuroxime among LRT isolates in children younger than five years of age, it would be prudent to use another antimicrobial for empirical treatment of severe pneumonia presumed to be pneumococcal in origin in young children. Physicians in our region also need to be aware of the cefotaxime NS rate of $9 \%$ among LRT isolates in children younger

\section{REFERENCES}

1. Schuchat A, Robinson K, Wenger JD, et al. Bacterial meningitis in the United States in 1995. New Engl Jf Med 1997;337:970-6.

2. Musher DM. Infections caused by Streptococcus pneumoniae: Clinical spectrum, pathogenesis, immunity and treatment. Clin Infect Dis 1992;14:801-9.

3. Parsons HK, Dockrell DH. The burden of invasive pneumococcal disease and the potential for reduction by immunisation. Int J Antimicrob Agents 2002;19:85-93.

4. Casey JR, Pichichero ME. Changes in frequency and pathogens causing acute otitis media in 1995-2003. Pediatr Infect Dis J 2004;23:824-8.

5. Stocks N, Turnidge J, Crockett A. Lower respiratory tract infections and community acquired pneumonia in adults. Aust Fam Phys 2004;33:297-301.

6. Zar HJ, Mulholland K. Global burden of pediatric respiratory illness and the implications for management and prevention. Pediatr Pulm 2003;36:457-61.

7. Hoban DJ, Doern GV, Fluit AC, Roussel-Delvallez M, Jones RN. Worldwide prevalence of antimicrobial resistance in Streptococcus pneumoniae, Haemophilus influenzae, and Moraxella catarrhalis in the SENTRY Antimicrobial Surveillance Program, 1997-1999. Clin Infect Dis 2001;32(Suppl 2):S81-S93.

8. Desa MN, Lin TK, Yasin RM, Parasakthi N. Penicillin susceptibility and molecular characteristics of clinical isolates of Streptococcus pneumoniae at the University of Malaya Medical Center, Kuala Lumpur, Malaysia. Int J Infect Dis 2003;7:190-7.

9. Johnson DM, Stilwell MG, Fritsche TR, Jones RN. Emergence of multidrug-resistant Streptococcus pneumoniae: Report from the SENTRY Antimicrobial Surveillance Program (1999-2003). Diagn Microbiol Infect Dis 2006;56:69-74.

10. Kyaw MH, Clarke S, Jones IG, Campbell H. Incidence of invasive pneumococcal disease in Scotland, 1988-99. Epidemiol Infect 2002;128:139-47.

11. Doern GV, Richter SS, Miller A, et al. Antimicrobial resistance among Streptococcus pneumoniae in the United States: Have we begun to turn the corner on resistance to certain antimicrobial classes? Clin Infect Dis 2005;41:139-48.

12. Karlowsky JA, Thornsberry C, Jones ME, Evangelista AT, Critchley IA, Sahm DF. Factors associated with relative rates of antimicrobial resistance among Streptococcus pneumoniae in the United States: Results from the TRUST Surveillance Program (1998-2002). Clin Infect Dis 2003;36:963-70.

13. Roussel-Delvallez M, Chardon H, et al. Change of pneumococcal resistance to antibiotics in adults between 1995 and 1997: A study in eight French counties. Int JAntimicrob Agents. 2002;19:389-96.

14. Powis J, McGeer A, Green K, et al. In vitro antimicrobial susceptibilities of Streptococcus pneumoniae clinical isolates obtained in Canada in 2002. Antimicrob Agents Chemother 2004;48:3305-11. than five years of age, which further complicates the issue of treatment. Amoxicillin continues to be an excellent first-line antimicrobial for the treatment of pneumococcal infections that are amenable to oral therapy.

Our study provides more evidence that regional variation in NS rates among pneumococcal isolates occurs, thus emphasizing the need for local surveillance of susceptibility patterns to provide clinically relevant information with regard to treatment options. Both isolates from young children and LRT isolates are more resistant to antimicrobials and thus prudent antimicrobial utilization remains important.

ACKNOWLEDGEMENTS: Funding for CASPER was obtained from the Alberta Children's Hospital Foundation and an unrestricted grant from Wyeth Canada. We thank the study staff and associates including Linda Hastie, Stephanie Hui, Tracie Lloyd, Janice Pitchko and Heather Semeniuk for their many contributions. We also thank Drs David Scheifele, Greg Tyrrell and Judy MacDonald for their review of the manuscript.

15. Dixon JM, Lipinski AE, Graham ME. Detection and prevalence of pneumococci with increased resistance to penicillin. CMAJ 1977;117:1159-61.

16. Low DE, de Azavedo J, Weiss K, et al. Antimicrobial resistance among clinical isolates of Streptococcus pneumoniae in Canada during 2000. Antimicrob Agents Chemother 2002;46:1295-301.

17. Chen DK, McGeer A, de Azavedo JC, Low DE. Decreased susceptibility of Streptococcus pneumoniae to fluoroquinolones in Canada. Canadian Bacterial Surveillance Network. N Engl J Med 1999;341:233-9.

18. Health Regions. 2007. <www.health.gov.ab.ca/regions/RHA_ comm3.html> (Version current April 1, 2008).

19. Clinical and Laboratory Standards Institute. Performance Standards for Antimicrobial Disk Susceptibility Tests, 9th edn. Approved standard M02-09. Clinical and Laboratory Standards Institutes: Wayne, Pennsylvania, 2006.

20. Clinical and Laboratory Standards Institute. Methods for Dilution for Antimicrobial Susceptibility Tests for Bacteria That Grow Aerobically, 7th edn. Approved standard M7-A7. Clinical and Laboratory Standards Institute: Wayne, Pennsylvania, 2006.

21. Clinical and Laboratory Standards Institute. Performance Standards for Antimicrobial Susceptibility Testing. 16th Informational Supplement, M100-S16. Clinical and Laboratory Standards Institute: Wayne, Pennsylvania, 2006.

22. Brown SD, Rybak MJ. Antimicrobial susceptibility of Streptococcus pneumoniae, Streptococcus pyogenes and Haemophilus influenzae collected from patients across the USA, in 2001-2002, as part of the PROTEKT US study. J Antimicrob Chemother 2004;54(Suppl 1):i7-15.

23. Pottumarthy S, Fritsche TR, Sader HS, Stilwell MG, Jones RN. Susceptibility patterns of Streptococcus pneumoniae isolates in North America (2002-2003): Contemporary in vitro activities of amoxicillin/clavulanate and 15 other antimicrobial agents. Int J Antimicrob Agents 2005;25:282-9.

24. White RL, Enzweiler KA, Friedrich LV, Wagner D, Hoban D, Bosso JA. Comparative activity of gatifloxacin and other antibiotics against 4009 clinical isolates of Streptococcus pneumoniae in the United States during 1999-2000. Diagn Microbiol Infect Dis 2002;43:207-17.

25. Kaplan S, Mason E, Wald E, et al. Decrease of invasive pneumococcal infections in children among 8 children's hospitals in the United States after the introduction of the 7-valent pneumococcal conjugate vaccine. Pediatrics 2004;113:443-9.

26. Black SB, Shinefield HR, Hansen J, Elvin L, Laufer D, Malinoski F. Postlicensure evaluation of the effectiveness of seven valent pneumococcal conjugate vaccine. Pediatr Infect Dis J 2001;20:1105-7.

27. Kyaw MH, Lynfield R, Schaffner W, et al. Effect of introduction of the pneumococcal conjugate vaccine on drug-resistant Streptococcus pneumoniae. N Engl J Med 2006;354:1455-63. 
28. Talbot T, Poehling K, Hartert T, et al. Reduction in high rates of antibiotic-nonsusceptible invasive pneumococcal disease in Tennessee after introduction of the pneumococcal conjugate vaccine. Clin Infect Dis 2004;39:641-8.

29. O'Brien KL, Dagan R. The potential indirect effect of conjugate pneumococcal vaccines. Vaccine 2003;21:1815-25.

30. McClure CA, Ford MW, Wilson JB, Aramini JJ. Expected benefits of pneumococcal vaccination in Canadian infants and children $<5$ years old. Can Commun Dis Rep 2006;32:45-54.

31. Kellner JD, Church DL, Macdonald J, Scheifele D, Tyrrell GJ, Vanderkooi OG. Streptococcus pneumoniae (SP) nasopharyngeal (NP) colonization: Trends over three years after introduction of 7 -valent pneumococcal conjugate vaccine (PCV7) in Canada. 5th International Symposium on Pneumococci and Pneumococcal Diseases, April 2006. Alice Springs, Australia, 2006.

32. Kellner JD, McGeer A, Cetron MS, et al. The use of Streptococcus pneumoniae nasopharyngeal isolates from healthy children to predict features of invasive disease. Pediatr Infect Dis J 1998;17:279-86.

33. Kellner JD, Scheifele D, Vanderkooi OG, Macdonald J, Church DL, Tyrrell GJ. Effects of routine infant vaccination with the 7-valent pneumococcal conjugate vaccine on nasopharyngeal colonization with streptococcus pneumoniae in children in Calgary, Canada. Pediatr Infect Dis J 2008;27:526-32.

34. Pelton SI, Huot H, Finkelstein JA, et al. Emergence of $19 \mathrm{~A}$ as virulent and multidrug resistant Pneumococcus in Massachusetts following universal immunization of infants with pneumococcal conjugate vaccine. Pediatr Infect Dis J 2007;26:468-72.

35. Messina AF, Katz-Gaynor K, Barton T, et al. Impact of the pneumococcal conjugate vaccine on serotype distribution and antimicrobial resistance of invasive Streptococcus pneumoniae isolates in Dallas, TX, children from 1999 through 2005. Pediatr Infect Dis J 2007;26:461-7.

36. Kellner JD. Outbreaks of serotypes 5 and serotype 8 invasive pneumococcal disease in Calgary, Alberta, Canada. ProMED-mail; 2006. <http://promedmail.org > (Version current at November 5, 2008).

37. Twele LG, Tyrrell GJ, Vanderkooi OG, et al. Large outbreak of serotype 5 invasive pneumococcal disease in predominately homeless persons in Calgary, Canada. 47th Interscience Conference for Antimicrobial Agents and Chemotherapy, September 2007. Chicago, IL, USA 2007.

38. Jones ME, Karlosky JA, Draghi DC, Thornsberry C, Dahm DF, Bradley JS. Rates of antimicrobial resistance among common bacterial pathogens causing respiratory, blood, urine, skin and soft tissue infections in pediatric patients. Eur J Clin Microbiol Infect Dis 2004;23:445-55.

39. Weiss K, Guilbault C, Cortes L, Restieri C, Low DE. Genotypic characterization of macrolide-resistant strains of Streptococcus pneumoniae isolated in Quebec, Canada, and in vitro activity of ABT-773 and telithromycin. J Antimicrob Chemother 2002;50:403-6.

40. Farrell DJ, Felmingham D, Shackcloth J, et al. Non-susceptibility trends and serotype distributions among Streptococcus pneumoniae from community-acquired respiratory tract infections and from bacteraemias in the UK and Ireland, 1999 to 2007. J Antimicrob Chemother 2008;62(Suppl 2):ii87-95.

41. Pichichero ME, Casey JR. Emergence of a multiresistant serotype $19 \mathrm{~A}$ pneumococcal strain not included in the 7 -valent conjugate vaccine as an otopathogen in children. JAMA 2007;298:1772-8.

42. Pai R, Moore MR, Pilishvili T, Gertz RE, Whitney CG, Beall B. Postvaccine genetic structure of Streptococcus pneumoniae serotype 19A from children in the United States. J Infect Dis 2005;192:1988-95.

43. Farrell DJ, Klugman KP, Pichichero M. Increased antimicrobial resistance among nonvaccine serotypes of Streptococcus pneumoniae in the pediatric population after the introduction of 7-valent pneumococcal vaccine in the United States. Pediatr Infect Dis J 2007;26:123-8.

44. Kellner JD, Vanderkooi OG, McDonald J, Church DL, Tyrrell GJ, Scheifele D. Changing epidemiology of invasive pneumococcal disease in Canada, 1998-2007: Update from the Calgary-area Streptococcus pneumoniae research (CASPER) study. Clin Infect Dis 2009;49:205-12.

45. Vanderkooi OG, Low DE, Green K, Powis JE, McGeer A. Predicting antimicrobial resistance in invasive pneumococcal infections. Clin Infect Dis 2005;40:1288-97.

46. Zhanel GG, Palatnick L, Nichol KA, Bellyou T, Low DE, Hoban DJ. Antimicrobial resistance in respiratory tract Streptococcus pneumoniae isolates: Results of the Canadian Respiratory Organism Susceptibility Study, 1997 to 2002. Antimicrob Agents Chemother 2003;47:1867-74.

47. Jones RN, Biedenbach DJ, Beach ML. Influence of patient age on the susceptibility patterns of Streptococcus pneumoniae isolates in North America (2000-2001): Report from the SENTRY Antimicrobial Surveillance Program. Diagn Microbiol Infect Dis 2003;46:77-80.

48. Hoban D, Baquero F, Reed V, Felmingham D. Demographic analysis of antimicrobial resistance among Streptococcus pneumoniae: Worldwide results from PROTEKT 1999-2000. Int J Infect Dis 2005;9:262-73.

49. Thornsberry C, Sahm DF, Kelly LJ, et al. Regional trends in antimicrobial resistance among clinical isolates of Streptococcus pneumoniae, Haemophilus influenzae, and Moraxella catarrhalis in the United States: Results from the TRUST Surveillance Program, 1999-2000. Clin Infect Dis 2002;34(Suppl 1):S4-S16. 


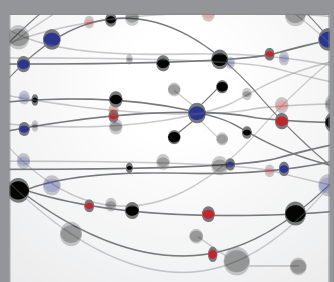

The Scientific World Journal
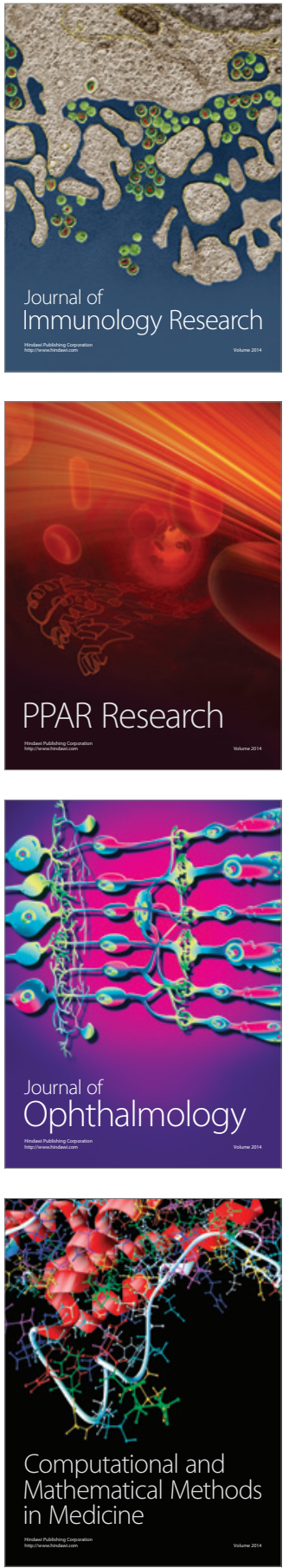

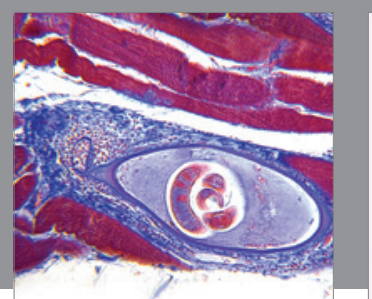

Gastroenterology Research and Practice

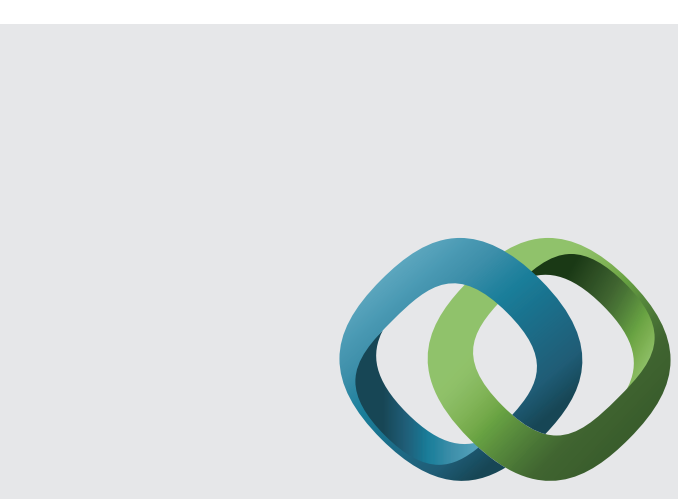

\section{Hindawi}

Submit your manuscripts at

http://www.hindawi.com
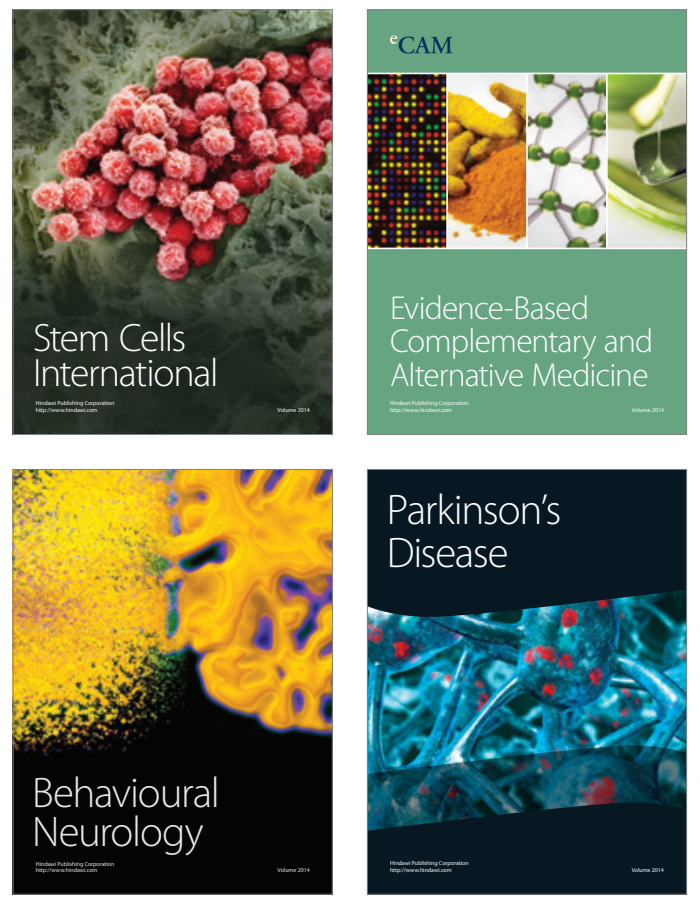
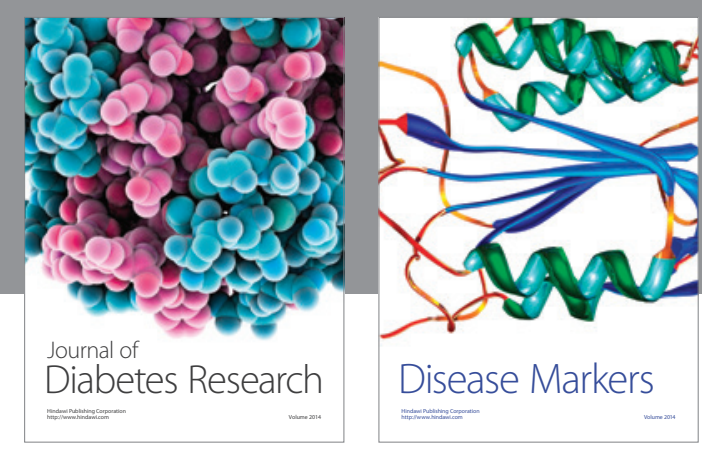

Disease Markers
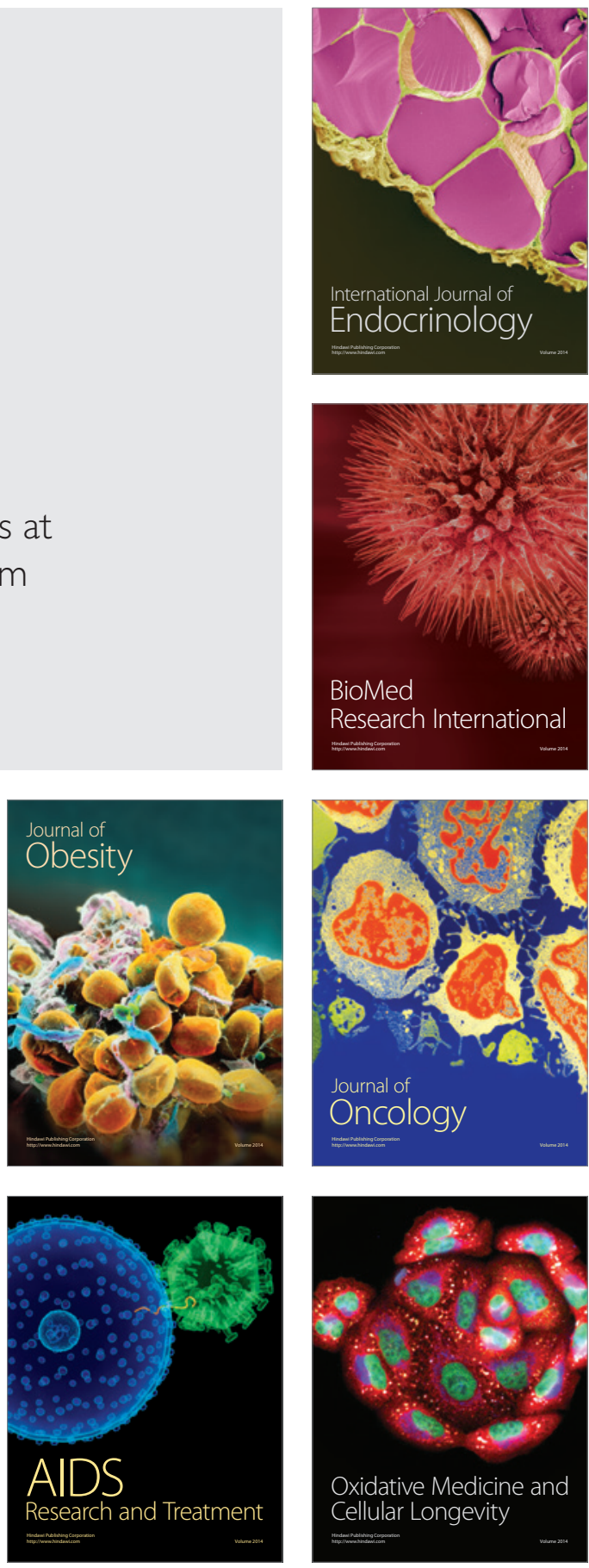